\title{
AS ATUAIS POLÍTICAS DE SAÚDE: OS RISCOS DO DESMONTE NEOLIBERAL
}

Laura Tavares Soares ${ }^{1}$

\section{INTRODUÇÃO}

A chamada área social - com destaque para a área da saúde - constitui-se hoje no terreno mais conflitivo e exposto da nossa sociedade, na medida em que é particularmente sensível às condições econômicas de restrição financeira impostas pelas políticas de ajuste neoliberal.

Estamos diante de uma situação social e de saúde onde a superposição de antigos e novos problemas configura um quadro de uma enorme perversidade e complexidade. A este quadro se agrega, ainda, uma situação de desmonte do Estado brasileiro, o que tem levado a uma crescente desresponsabilização do governo federal das suas atribuições no terreno social.

As políticas de ajuste, determinadas em Cabe, portanto, retomar a defesa do SUS, resgatando seus princípios constitucionais de universalidade, integralidade e acesso igualitário a todos os níveis de complexidade do sistema, garantindo a qualidade da atenção por equipes profissionais qualificadas e com condições de trabalho. Isto não é pouco, face ao explícito e implícito processo de desmonte que o nosso sistema de saúde vem sofrendo.

âmbito federal, têm trazido enormes limitações para as unidades da federação - em particular os municípios - no que diz respeito às respectivas capacidades de intervenção e de resposta frente às crescentes demandas sociais e de saúde. Isto tem gerado grandes iniqüidades, aprofundando ainda mais o quadro de desigualdade social.

As políticas sociais e de saúde perderam sua dimensão integradora, tanto no âmbito nacional como no âmbito regional/estadual, caindo numa visão focalista onde o local é privilegiado como o único espaço capaz de dar respostas supostamente mais "eficientes" e acordes às necessidades da população (não por acaso reduzida hoje a "comunidade"). Retrocedemos a uma visão "comunitária" onde as pessoas e as famílias passam a ser as responsáveis últimas por sua saúde e bem estar. Por trás de um falso e importado conceito de "empowerment" está o abandono por parte do Estado de seu papel ativo e determinante nas condições de vida da população, particularmente quando parcelas majoritárias e crescentes da mesma estão na mais absoluta pobreza.

Este é o contexto onde se desenrola a atual Política de Saúde hoje no Brasil, o qual não pode ser ignorado sob pena de cairmos no reducionismo de soluções tecnocráticas para o setor saúde e na aceitação acrítica de programas federais verticais e autoritários travestidos de "inovadores" e "modernos".

\section{A PROPOSTA DE REFORMA DO ESTADO NO CONTEXTO NEOLIBERAL}

As chamadas "reformas constitucionais" vêm sendo perpetradas no Brasil desde o início da década de 90, sob o argumento de que a Constituição Cidadã de 1988 seria o principal empecilho ao processo de "modernização" e "abertura" do país. No entanto, é no governo FHC que se completa o projeto mais acabado (e neoliberal) de "Reforma do Estado".

1 Enfermeira, Sanitarista, Doutora em Economia do Setor Público na área de Política Social pela UNICAMP Professora da UFRJ; Assessora do Laboratório de Políticas Públicas da UERJ;: Autora dos livros "Ajuste Neoliberal e Desajuste Social na América Latina" e "Os Custos Sociais do Ajuste Neoliberal na América Latina" 
Em primeiro lugar gostaríamos de chamar a atenção para alguns aspectos preliminares ao debate em torno da atual reforma administrativa proposta pelo Executivo, tais como:

- As utilizações que têm sido feitas pelo governo federal, devidamente sustentadas pela mídia, do termo REFORMA, emprestando-Ihe um caráter "mágico e infalível" na solução de todos os problemas nacionais.

- A necessidade de definir melhor, com mais clareza, qual é o ESTADO objeto da Reforma e que aspectos precisam ser reformados; não sendo possível, dessa forma, impor uma receita padrão de reforma, assumindo, portanto, que existem diferentes possibilidades e propostas de REFORMA (em contraposição à "via única");

- Qual é o DIAGNÓSTICO no qual se baseia a reforma e quais as suas propostas de resolução dos problemas - falsas premissas levando a falsas soluções (o exo. claro disto é a culpabilização dos funcionários públicos por uma série de problemas no aparelho de Estado, o que tem focalizado as propostas da reforma exclusivamente em cima do funcionalismo).

- A não existência de uma REFORMA "NEUTRA", que seja adequada e boa para todo o país ou seja, toda reforma atende a determinados interesses - este é sem dúvida um aspecto central na discussão e trata da questão política da Reforma: qual é o projeto político que está por trás da Reforma do Estado, amparado por quem.

- Quais as perspectivas e os possíveis resultados da Reforma ? Esta é uma grande interrogação, com algumas possibilidades de previsão.

A primeira observação a ser ressaltada da análise dos documentos da reforma é a sua conotação meramente "administrativa", não se constituindo em uma verdadeira Reforma do Estado, não tocando sequer em problemas de fundo como o padrão de financiamento do Estado, a sua capacidade em minimizar as profundas desigualdades sociais e econômicas do país através de políticas de distribuição de renda e equalização do acesso a serviços públicos essenciais, etc, etc. A estratégia central da reforma em questão resume-se à substituição da "administração burocrática" pela "administração gerencial".

Por outro lado, a criação de um Ministério MARE - Ministério de Administração e Reforma do Estado - para reformar o próprio Estado lembra o Ministério da Desburocratização, gerando uma nova burocracia para reformar-se a si própria ou para desburocratizar-se a si própria.

O primeiro documento do MARE foi o Plano Diretor de 1995, documento "mãe" a partir do qual são gerados todos os demais. As premissas aí apontadas demonstram de forma clara o diagnóstico no qual se baseiam as propostas. A causalidade do agravamento da crise fiscal e da inflação é totalmente atribuída à presença do Estado no setor produtivo. Dessa forma, a Reforma do Estado passa a ser apenas um instrumento para "consolidar a estabilização e assegurar o crescimento sustentado da economia".

Para implementar-se uma administração "de caráter gerencial" que permita "formas modernas" de gestão, basta apenas, segundo o documento supracitado, "flexibilizar" a estabilidade e os regimes jurídicos dos servidores, acrescentando, em seguida, também como "essencial" que as aposentadorias dos servidores ocorram em "idade razoável" e proporcionais ao tempo de contribuição.

A teoria do "desvio" do Estado de suas funções perpassa todo o documento. Dessa forma, o Estado ao "desviar-se" passa a não dar conta da "sobrecarga de demandas", particularmente as sociais, gerando uma "ingovernabilidade"2 e configurando uma "crise do Estado". O eixo de determinação aqui se inverte: é essa incapacidade do Estado em processar a sobrecarga de demandas que gera a desordem e a desaceleração econômica. Esta tese é muito semelhante àquela difundida nos anos 70 nos países desenvolvidos pelos conservadores de que era a crise do "Welfare State" que levava à crise econômica.

A definição do que seja a Crise do Estado daí derivada é completamente diferente da que apresentamos anteriormente ${ }^{3}$. Os aspectos constituintes dessa crise definidos pelo MARE são: 1 - 0

2 Que o MARE chama de problema de "governança", na medida em que sua capacidade de implementar as políticas públicas seria limitada pela "rigidez e ineficiência da máquina administrativa".

${ }^{3}$ Ver Crise do Estado Desenvolvimentista com base nas análises feitas por José Luis Fiori. 
aspecto fiscal, entendido como perda de "poupança" pública (financiamento e endividamento são termos que sequer são mencionados); 2 - o esgotamento da "estratégia estatizante" (?) de intervenção do Estado, centrando fogo, mais uma vez, na crise do "Estado de Bem Estar Social"; e 3 - a forma "burocrática" de administrar o Estado.

Em decorrência desse diagnóstico da Crise, o MARE coloca como "inadiáveis" os seguintes pontos: ajustamento fiscal (note-se que não se trata de uma reforma fiscal no sentido mais amplo, a qual, por sinal, está "adiada" sine die); reformas econômicas "orientadas para o mercado" que, supostamente, garantiriam a "concorrência interna" e condições para o "enfrentamento da competição internacional" (!); reforma da previdência social, a qual tem como propósito fundamental "retirar privilégios" cortando, na prática, benefícios e gastos; reforma do aparelho de Estado com vistas a aumentar a "governança".

O movimento básico para corrigir as "distorções" ou os "desvios" do Estado é a transferência para o setor privado daquelas atividades que podem ser "controladas pelo mercado". Isto é feito através da privatização de todas as estatais (sem nenhum tipo de distinção entre elas nem uma caracterização das mesmas enquanto papel estratégico do Estado no desenvolvimento nacional) e da descentralização da execução de serviços (sociais) de educação, saúde, cultura e pesquisa científica a um setor "público não-estatal". Este setor emerge do documento do MARE sem que se defina claramente como ele é constituído e quais serão as regras (se é que elas existirão) para o seu funcionamento e, principalmente, para o seu financiamento. O único critério mencionado é o fato da Instituição ser considerada como de "utilidade pública", critério este que, como sabemos, tem sido alvo de todo tipo de corrupção e clientelismo, incluindo aí entidades como a "Golden Cross" e clubes de futebol, entre outras pérolas.

Esse movimento mais geral se traduz em três dimensões de intervenção: a INSTITUCIONAL LEGAL, onde se trata de remover os obstáculos legais/constitucionais, superando a "rigidez" (aqui a palavra chave é FLEXIBILIZAR); a dimensão CULTURAL (trata-se de superar a "cultura burocrática"), e a GERENCIAL, considerada a "dimensão-chave" da reforma administrativa.

Na dimensão Institucional - Legal estão previstas as Emendas Constitucionais. A primeira é sobre o Capítulo da Administração Pública, onde todas as mudanças são dirigidas aos servidores públicos - "flexibilizando" as relações de trabalho e as regras de aposentadoria por um lado, e tornando mais "rígidas" as limitações salariais e proventos das aposentadorias (aqui, ao contrário dos direitos, não há problema em tornar as regras mais "rígidas"). Uma segunda estabelece a "autonomia" entre os três Poderes no que diz respeito à organização administrativa e fixação dos vencimentos de seus servidores, ou seja, o fim da isonomia. A Emenda da Previdência é considerada como estratégica nessa dimensão. Quanto à Legislação Infra-Constitucional, esta também se encontra, na quase totalidade, dirigida aos servidores.

A segunda dimensão é a chamada dimensão cultural, que inclui a transição para uma administração pública gerencial sem nenhuma outra definição mais precisa.

Na terceira e última dimensão, referente à gestão é onde se encontram as propostas mais concretas e desenvolvidas. São três projetos em curso: Avaliação Estrutural, Agências Autônomas e Organizações Sociais

A Avaliação Estrutural operaria horizontalmente, extinguindo, privatizando e descentralizando (transferindo para o tal setor "publico não estatal") órgãos públicos.

As chamadas Agências Autônomas operariam de forma vertical, transformando Autarquias e Fundações em Agências Autônomas, com o propósito de "modernizar a gestão", estabelecendo uma "seleção prévia" e a criação de "laboratórios de experimentação".

A estratégia mais adiantada é a das Organizações Sociais, que também operariam verticalmente, descentralizando serviços considerados como não-exclusivos do Estado partindo do pressuposto que esses serviços serão mais "eficientemente" realizados se, mantendo o financiamento do Estado, forem executados pelo tal setor público não-estatal.

As Organizações Sociais(O.S.) definidas como "entidades de direito privado que, por iniciativa do Poder Executivo, obtém autorização legislativa para celebrar contrato de gestão com esse poder, e assim ter direito à dotação orçamentária". Elas terão autonomia financeira e administrativa, 
respeitadas as condições descritas em lei como, por exemplo, a composição de seus conselhos de administração. Além dos recursos orçamentários, podem obter outros ingressos através de prestação de serviços, doações, legados, financiamentos, etc.

Essa suposta "autonomia" financeira e administrativa, pode implicar em sua total subordinação a interesses privados locais, comprometidos ou não com a entidade que passa a denominar-se O.S. O suposto controle social sobre a mesma dar-se-ia através do chamado Conselho de Administração o qual, muito provavelmente, ficará comprometido com os interesses acima mencionados.

Na realidade, a definição de uma maior "parceria" com a sociedade enfatiza que esta última deverá financiar uma parte menor, mas significativa, dos custos dos serviços prestados. No caso de serviços sociais essenciais, como o são os hospitais (ver "prioridades" abaixo), isto provocará, de saída, uma dualização da clientela - discriminando entre aqueles que podem e os que não podem pagar - e dos serviços prestados - de maior ou menor qualidade dependendo do poder de compra do usuário. Elimina-se, com essa proposta, o princípio da UNIVERSALIDADE, previsto (ainda) na Constituição, onde todo e qualquer cidadão tem o DIREITO de ter acesso a serviços sociais básicos, no caso de saúde, de boa qualidade e em todos os níveis de complexidade.

A transformação dos serviços não-exclusivos estatais em O.S. se dará de forma "voluntária" a partir "da iniciativa dos respectivos ministros, através de um Programa Nacional de Publicização. Terão "prioridade" os hospitais, as universidades e escolas técnicas, os centros de pesquisa, as bibliotecas e os museus. Esse caminho "voluntário" de criação de Organizações Sociais, a critério dos ministros, aumenta ainda mais o extenso rol de dúvidas e incertezas acerca desse processo de "Reforma do Estado". Por esse caminho ficam abolidos os critérios de planejamento e equalização de serviços sociais essenciais cujo acesso se tornará ainda mais desigual. Também a transparência desse processo fica prejudicada e a "iniciativa dos ministros" muito provavelmente será a de proteger seus apadrinhados em seus respectivos estados e municípios.

Essas estratégias de "Reforma do Estado" estão inseridas em um movimento mais geral em direção a um suposto setor público não-estatal (também chamado de "Terceiro Setor") que se responsabilizaria pela execução dos serviços que não envolvessem o exercício do "poder de Estado", mas que deveriam ser subsidiados pelo Estado, como é o caso dos serviços de educação, saúde, cultura e pesquisa científica. Esse processo, chamado de "publicização", na realidade não é uma "criação" do MARE. Ele se inclui em todas as propostas de reforma decorrentes da implementação dos chamados Ajustes Estruturais. No entanto, mesmos naqueles países onde já existia uma certa tradição na participação de entidades não-estatais na prestação de serviços sociais, esse modelo vem sendo criticado na medida em que não está dando conta de compensar a forte retração dos respectivos Estados tanto no financiamento como na gestão dos serviços públicos. O maior exemplo disso é os Estados Unidos onde amplos setores da população encontram-se marginalizados do acesso a serviços sociais básicos, sejam eles estatais ou não.

\section{POLÍTICA DE SAÚDE NO CONTEXTO NEOLIBERAL: IMPLICAÇÕES E PROBLEMAS}

\section{O FINANCIAMENTO DO SETOR SAÚDE}

Ao contrário do que muitos afirmam, a política de saúde não está imune ao contexto neoliberal que vem sendo imposto em nosso país na última década. A mais evidente das restrições tem sido a financeira, que vem reduzindo de forma sistemática o gasto per capita em saúde no Brasil, cujo patamar encontra-se abaixo de países latino americanos mais pobres que o nosso.

Os escassos recursos têm sido mal distribuidos, sem respeitar a heterogeneidade regional e as reais necessidades da população. Acreditar que dez reais per capita ano (correspondentes ao mal chamado $\mathrm{PAB}$ ) são suficientes para dar uma atenção básica integral e de qualidade à população é uma afronta! $O$ alto custo e a assistência hospitalar de má qualidade e de baixa resolutividade continuam consumindo a maior parte dos recursos. O financiamento calcado na mera produção de serviços impede, de forma definitiva, a solução das chamadas "distorções" do sistema. O repasse de recursos tem imposto aos estados e, sobretudo, aos municípios, uma "camisa de força" que os obriga a cumprir com uma infinidade de portarias ministeriais, cujas fórmulas tecnocráticas impõem um padrão uniforme 
para realidades políticas, administrativas, financeiras e sociais totalmente diversas.

Na realidade, houve uma brutal reconcentração de recursos e de poder nas mãos do governo federal, totalmente contrária ao ideário do SUS na sua matriz originária. Abandonou-se por completo a concepção - prevista na Constituição de 1988 - de Seguridade Social, que preconizava um orçamento único e com diversidade de fontes de financiamento para os seus componentes de Saúde, Assistência e Previdência Śocial. Ao restringir o fiananciamento do Setor Saúde apenas aos recursos fiscais, ele ficou à mercê da política de ajuste fiscal cada dia mais restritiva, lançando mão de recursos aleatórios, como a CPMF, de caráter contingencial e que sequer vem sendo integralmente destinada ao setor.

Os parcos investimentos feitos pelo governo federal (diga-se de passagem, exclusivamente destinados a reequipar, parcialmente, a rede hospitalar já existente) dependem de empréstimos externos (principalmente do Banco Mundial), os quais, além de eventuais, aumentam ainda mais a dívida do nosso país, que já não é pequena, como todos sabem.

\section{FINANCIAMENTO DO SETOR SAÚDE - A PEC DE SET. DE 2000}

A recém promulgada PEC da Saúde é mais um exemplo da capacidade de distorcer propostas antes defendidas pela esquerda e setores progressistas e transformá-las em estratégias convenientes para o projeto neoliberal. Mais uma vez, sob a aparência de que os recursos para a saúde aumentarão, e concedendo de forma distorcida uma aspiração de vinculação de recursos, o governo federal perpetra mais uma "reengenharia", reduzindo sua obrigação e repassando para os estados e municípios a responsabilidade maior no financiamento do setor saúde.

Do ponto de vista da União, aumentar em $5 \%$ o montante investido no setor em relação ao ano passado (1999), corrigindo para os anos seguintes pela variação do PIB nominal, não só não significa nenhum avanço no sentido de resolver a insuficiência de recursos para a saúde, como se trata de um enorme retrocesso com relação à Constituição de 1988 e à PEC original dos deputados Eduardo Jorge e Waldir Pires, pelas seguintes razões:

- A PEC atual não define a origem dos recursos no âmbito federal, eliminando de vez a vinculação de recursos da Seguridade Social para a Saúde, na medida em que os recursos investidos no setor desde 1993 são apenas de origem fiscal.

- A ameaça de extinção total das Contribuições pelas propostas em pauta para a Reforma Tributária confirma a destruição da concepção original de Seguridade Social no financiamento eqüitativo da Saúde, Previdência e Assistência Social.

- O patamar de recursos sobre o qual será corrigido em $5 \%$ é sabidamente insuficiente para a saúde. Além de manter esse patamar baixo, o acréscimo de um PIB nominal em franco descenso da recessão econômica tampouco representa nenhum cenário animador.

- Os mecanismos de transferência e de aplicação dos recursos por parte do governo federal mantêm as mesmas distorções já apontadas.

Do ponto de vista dos estados, a PEC implica em uma pequena elevação da sua participação. Este acréscimo, no entanto, provavelmente não compensará, de um lado, a provável retração de alguns municípios que já destinam mais do que está previsto na PEC; e, de outro, a diminuição dos recursos federais pela retirada das contribuições. Além disso, mais uma vez impõe-se uma camisa de força uniforme como se todos os estados tivessem iguais condições de aplicar pelo menos $7 \%$ de suas receitas de impostos e transferências constitucionais, ignorando a retração econômica que afeta a principal fonte de receita dos estados - o ICMS - isso sem falar no crescente processo de endividamento dos estados. Nesse sentido, não foi estabelecido nenhum tipo de compensação

Finalmente, do ponto de vista dos municípios, a vinculação de $7 \%$ até $15 \%$ não provocará nenhum aumento de recursos para a saúde: boa parte dos municípios brasileiros já contribui, em média, com $15 \%$ de suas receitas de impostos e transferências ${ }^{4}$. Ou seja, provavelmente a Lei de Responsabilidade Fiscal afetará o nível do gasto municipal já alcançado na área da saúde, na medida

${ }^{4}$ Ver levantamento do MS feito em 1998 junto a 1.500 municípios (SIOPS - Sistema de Informações sobre o Orçamento Público em Saúde). 
em que o corte de despesas ocorrerá certamente junto às chamadas "despesas comprimíveis".

Por outro lado, é totalmente desconsiderada a enorme heterogeneidade entre os municípios brasileiros na sua capacidade de arrecadação, sobretudo no que diz respeito à suposta "compensação" concedida aos municípios para criar o IPTU "progressivo", fonte que para os municípios pobres não representa absolutamente nada. Ou seja, confirma-se, de forma recorrente, a nossa tese de que a desigualdade entre os municípios será mantida, possivelmente ampliando a iniqüidade do ponto de vista da oferta de serviços de saúde em qualidade e quantidade. Finalmente, a definição do gasto em saúde do ponto de vista da atenção básica e os mecanismos de repasse permanecem inalterados com essa "nova" PEC.

\section{A DESCENTRALIZAÇÃO OU A MUNICIPALIZAÇÃO A QUALQUER CUSTO}

A descentralização na década de 90 segue-se ao desmonte dos programas sociais federais iniciado em 1989. No decorrer da década, ela assume uma face neoliberal, condizente com a política e a ideologia dominantes, totalmente contrária ao preconizado pela Constituição de 1988.

Tem sido um processo atabalhoado, marcado por um contexto de ajuste recessivo das contas públicas, repassando de forma acelerada encargos e responsabilidades diretamente para os municípios, muitos dos quais incompatíveis com as suas distintas realidades e possibilidades.

Esse processo tem apresentado os seguintes problemas:

- A descentralização de encargos não é acompanhada de forma equivalente pela descentralização de recursos em quantidade e qualidade, com fluxos irregulares, e sem respeitar as reais necessidades de saúde bem como as heterogêneas capacidades de intervenção das Prefeituras e órgãos municipais.

- Essa descentralização tem provocado o desmonte de estruturas/equipamentos sociais federais e/ou estaduais pré-existentes, sem que as prefeituras sejam capazes de mantê-los ou substituí-los por algo equivalente.

- O processo de descentralização não tem levado em conta a complexidade dos problemas sociais em determinadas regiões (como por exemplo as metropolitanas) cuja dimensão é supramunicipal e exige uma intervenção articulada e regional.

- As iniqüidades regionais têm aumentado com o processo de descentralização entendido apenas como "municipalização", na medida em que tem provocado a fragmentação das ações e a diminuição da sua efetividade.

Os estados têm sido práticamente ignorados nessa descentralização/municipalização enquanto agentes responsáveis pela implementação de políticas regionais, limitando-se a um papel meramente formal de repassadores de recursos. É preciso resgatar a capacidade dos estados enquanto unidades da federação que devem (re) assumir uma responsabilidade estratégica na condução das políticas públicas de saúde no âmbito estadual/regional.

Trata-se de uma municipalização a qualquer preço, totalmente distinta daquela proposta pelo SUDS nos anos 80 e consagrada na Constituição de 1988, que previa uma autonomia real das unidades federada, baseada em um esquema de financiamento e repasse de recursos compatível com o gradual repasse de encargos, bem como na responsabilidade compartilhada entre os três níveis de governo.

É preciso olhar para o processo real de municipalização que hoje está se dando no SUS, face ao contexto restritivo do ajuste e diante das propostas de reforma do Estado dirigidas à privatização e à focalização dos serviços públicos para os "pobres".

A atual política de saúde, não por acaso, centra seu foco de atenção no âmbito municipal/local, impondo padrões de atuação não condizentes com a enorme heterogeneidade deste país, e totalmente distantes das possibilidades reais dos municípios de darem resposta aos crescentes problemas de saúde com os quais se defrontam.

\section{A PRIVATIZAÇÃO E AS “INOVAÇÕES GERENCIAIS”}

A privatização da saúde no Brasil tem várias faces: algumas mais explícitas outras, em sua maioria, ocultas ou travestidas de "modernização gerencial".

Uma de suas faces mais perversas é o próprio financiamento do setor, que privilegia velhos e 
novos "atores" no cenário da prestação privada de serviços de saúde: os hospitais e clínicas particulares conveniadas com o SUS e os seguros privados de saúde.

O primeiro grupo, ainda que de forma declinante, dado o irrisório preço pago pelas AIHS, ainda consome parte importante dos recursos destinados ao SUS, com a agravante de ser o responsável pelas famosas "distorções" e "desvíos" de recursos, principalmente no âmbito local, já que são as Prefeituras as responsáveis pelo pagamento das internações hospitalares no seu território. Ao contrário do que reza a "cartilha", os governos locais têm se mostrado tão corruptos quanto os demais níveis de governo e igualmente imunes ao controle social supostamente exercido pelos Conselhos Municipais de Saúde, muitas vezes manipulados pelos respectivos prefeitos e/ou secretários municipais de saúde.

O segundo grupo - os seguros privados de saúde - se constitui no "setor emergente", expressão máxima da mercantilização da saúde. Trata-se de um setor duplamente beneficiado. De um lado pela política de desmonte do SUS que "expulsa" clientela potencial para esses seguros: ou seja, com a sua política, o governo federal assegura um patamar de demanda para esses seguros. De outro, ele é privilegiado por um financiamento direto e indireto através de subsídios e isenções fiscais, o que tem representado um enorme desvio de recursos públicos para esse setor, abertamente lucrativo, em detrimento do SUS.

Cabe apenas lembrar que esse privilegiamento tem limitações sérias, de natureza estrutural e financeira, já demonstradas em países onde se privatizou por completo o setor saúde (como é o caso do Chile). Nos países latinos americanos, e o nosso não foge à regra, as possibilidades de expansão da demanda dos seguros privados é limitada à própria renda, particularmente da classe média, a qual, inclusive, vem empobrecendo a olhos vistos. Ou seja, esse setor tem um potencial de cobertura máxima em torno de $30 \%$ da população. Isto significa que os restantes $70 \%$ (os mais empobrecidos) continuarão dependendo do sistema público, cada dia mais desmontado e desfinanciado. Por outro lado, a capacidade de financiamento público desse setor também tem um limite, já que representa um custo muito elevado para os cofres públicos.

Finalmente, acrescente-se que o poder regulatório por parte do poder público sobre os seguros privados tem se mostrado extremamente limitado: é do conhecimento de todos as inúmeras restrições feitas por esse setor a determinadas clientelas e patologias que não dão lucro, sem falar na baixa qualidade da assistência prestada pelos serviços médicos contratados pelas companhias seguradoras, os quais são péssimamente remunerados, mais uma vez, em função dos lucros absurdos auferidos por essas empresas.

Outra face tão perversa quanto, mas talvez mais "camuflada", tem sido a privatização "por dentro" do setor público. É a introdução da lógica mercantil no interior dos serviços públicos, aonde se privilegia a "microeconomia" do custo/benefício em detrimento da qualidade. São os "modismos" gerenciais, como a "qualidade total" e outras bobagens, que, entre outras coisas, provocam a eliminação do servidor público através da "flexibilização" e da "desregulamentação", gerando um total descompromisso do serviço com a população atendida. As formas assumidas por essa "modernidade gerencial" são variadas, sendo as mais conhecidas as chamadas "cooperativas".

Esta é uma estratégia já explicitada na mal chamada "Reforma do Estado", que transforma órgãos públicos estatais em agências privadas denominadas de "Organizações Sociais", eufemismo que representa o descompromisso do Estado com a saúde da população, entregando-a nas mãos de agentes privados os quais, obviamente, são devidamente alavancados por recursos públicos. Em nome da "liberdade de escolha", essas agências podem, se quiserem, cobrar do pobre usuário que estará pagando duplamente: através dos impostos e do pagamento direto pelos serviços.

Aqui cabe chamar a atenção para o fato de que, lamentavelmente, essa estratégia da cobrança direta - preconizada em inúmeros documentos do Banco Mundial - já está sendo amplamente utilizada na maioria dos países latino americanos. Isto significa que ainda temos muito que defender em nosso país: o SUS ainda é o único sistema público universal da América Latina, e, apesar das suas restrições e problemas, continua sendo a única alternativa que resta à parcela majoritária da nossa população.

\section{OS ATUAIS “MODELOS ASSISTENCIAIS” EM SAÚDE: AVANÇO OU RETROCESSO?}


Para finalizar, não se pode deixar de analisar e criticar os atuais Programas Federais de Saúde, com o devido destaque para o PACS (Programa de Agentes Comunitários de Saúde) e o PSF (Programa de Saúde da Família). Estes programas têm sido o "carro-chefe" daquilo que vem sendo denominado de "reversão do modelo assistencial". Do meu ponto de vista esta "reversão" tem sido para pior pelas seguintes razões:

- Em primeiro lugar, são programas verticais, impostos de cima para baixo pelo Ministério da Saúde, totalmente normatizados no nível central, e bancados por "incentivos" financeiros no repasse de recursos, obrigando, na prática, a sua adoção por parte dos Municípios.

São programas que desconsideram totalmente a enorme heterogeneidade entre os municípios na oferta de serviços de saúde - a maioria dos quais sequer possui uma rede regionalizada e hierarquizada que garanta o acesso universal a todos os níveis de atenção - o que limita o atendimento dado por esses programas a uma simples "porta de entrada", sem resolutividade e sem "porta de saída".

- Desconsideram, ainda, o também heterogêneo e complexo quadro epidemiológico brasileiro que demanda serviços de saúde em todos os níveis de complexidade: os "pobres" hoje estão morrendo de acidentes e violências, câncer, doenças cardiovasculares, problemas cuja resolução vai muito além da capacidade de um agente de saúde.

- Finalmente, e trazendo um problema que é muito caro à Enfermagem Brasileira, esses programas, na prática, têm substituído profissionais qualificados por pessoas sem qualificação, com uma remuneração praticamente simbólica, com contratos de trabalho precários, sob o falso argumento de que esses agentes estariam mais "próximos" da comunidade. Quem conhece a realidade e trabalha nesses programas sabe das inúmeras distorções que essa falsa premissa tem provocado, como os mecanismos de cooptação e o clientelismo nas contratações, somando-se as já mencionadas limitações desses agentes na resolução dos problemas de saúde da população.

Cabe, portanto, retomar a defesa do SUS, resgatando seus princípios constitucionais de universalidade, integralidade e acesso igualitário a todos os níveis de complexidade do sistema, garantindo a qualidade da atenção por equipes profissionais qualificadas e com condições de trabalho. Isto não é pouco, face ao explícito e implícito processo de desmonte que o nosso sistema de saúde vem sofrendo. 